Goldschmidt 2021 Abstract

https://doi.org/10.7185/gold2021.7796

\section{Crystallization of a Model Silicate} Moon

EDWARD BAKER ${ }^{1}$, JON WADE ${ }^{1}$ AND BERNARD J WOOD $^{2}$

${ }^{1}$ University of Oxford

${ }^{2}$ Earth Sciences, University of Oxford

Presenting Author: edward.baker@seh.ox.ac.uk

The Moon is almost indistinguishable from the Earth in a number of refractory isotope systems (e.g. W, O, Cr etc.), indicating a close genetic link between the Earth and Moon. Although broadly similar to the terrestrial mantle, the silicate Moon's major element composition appears to differ - the estimated iron content of the silicate Moon (up to $17 \mathrm{wt} \%$ $\mathrm{FeO}[2])$ is higher than Earth's ( 8 wt.\% FeO). The elevated lunar $\mathrm{FeO}$ estimate is based upon interpretations of lunar surface rocks.

Given the genetic link between the Earth and Moon, do lunar surface rocks require a mantle source that is significantly richer in iron? Could the silicate Moon be the same as the terrestrial mantle at the time of the giant impact?

Our experiments investigate a fractionally crystallizing lunar magma ocean of fertile pyrolite composition[1], with volatiles ( $\mathrm{K}$ and $\mathrm{Na}$ ) reduced by $67 \%$. At each step, the melt from the previous experiment was taken as the bulk composition for the next step. Experiments lie between an $\mathrm{fO} 2$ of $\mathrm{C}-\mathrm{CO}$ and $\mathrm{IW}+1$ in graphite capsules and follow the lunar pressure gradient, from $2.5-0.5 \mathrm{GPa}$ and $1675-850^{\circ} \mathrm{C}$.

The crystal phases produced along the liquid line of descent (fig. 1 ), when remelted, are able to reproduce the major element compositions of lunar rocks: Explicitly, a lunar mantle, of peridotitic composition, when crystallizing under lunar conditions, is able to reproduce our observations of the surface of the Moon.

On the Moon, the 'Bow-shaped' REE trends require a HREE enriched source; A high-temperature pyroxene is found experimentally to accept HREEs. Forward models of the REE evolution of the Moon suggest further differentiation of latestage liquids is required to deplete Fe and enrich REEs, in the melt, to recreate the KREEP basalt composition.

Re-mixing and recombination modelling finds that there is no requirement to enrich the Moon in refractory elements to reproduce the Apollo observations.

[1] Mcdonough, W. F. \& Sun, S. Chem. Geol. 120, 223-253 (1995)

[2] Jolliff, B. L., Wieczorek, M. A., Shearer, C. K., \& Neal, C. R. (2006). New views of the Moon. American Mineralogist, 60.

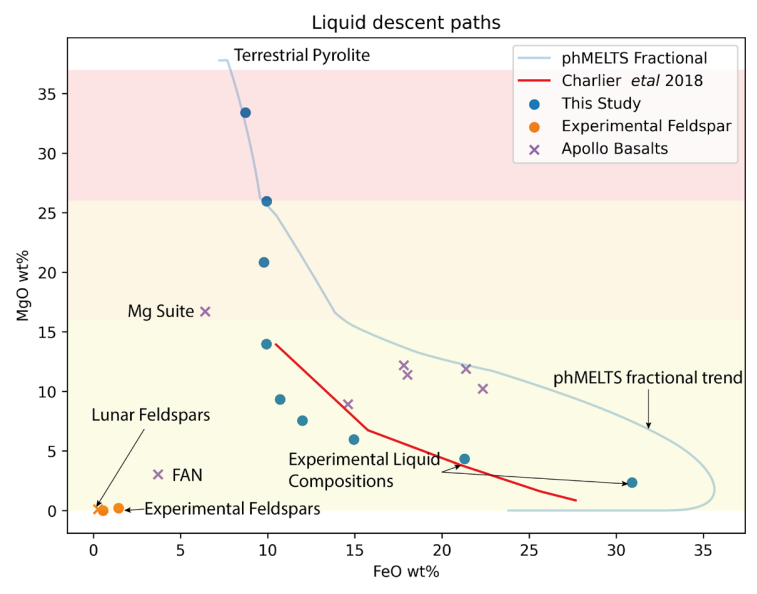

